\title{
Which is the best antiaggregant or anticoagulant therapy after TAVI? A propensity-matched analysis from the ITER registry. The management of DAPT after TAVI
}

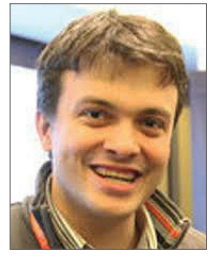

Fabrizio D’Ascenzo ${ }^{1 *}, \mathrm{MD}$; Umberto Benedetto ${ }^{2}, \mathrm{MD}$; Matteo $\mathrm{Bianco}^{3}, \mathrm{MD}$; Federico Conrotto ${ }^{1}, \mathrm{MD}$; Claudio Moretti ${ }^{1}, \mathrm{MD}$; Augusto D'Onofrio ${ }^{4}, \mathrm{MD}$; Marco Agrifoglio ${ }^{5,6}, \mathrm{MD}$; Antonio Colombo ${ }^{7}, \mathrm{MD}$; Flavio Ribichini ${ }^{8}, \mathrm{PhD}$; Giuseppe Tarantini', MD; Maurizio D'Amico ${ }^{1}$, MD; Stefano Salizzoni ${ }^{1}$, MD; Mauro Rinaldi ${ }^{1}$, MD; on behalf of the ITER Investigators

\begin{abstract}
1. Dipartimento di Scienze Mediche, Divisione di Cardiologia, Città della Salute e della Scienza, Turin, Italy; 2.Bristol Heart Institute, University of Bristol, School of Clinical Sciences, Bristol, United Kingdom; 3. A.O.U San Luigi Gonzaga, Division of Cardiology, Orbassano, Turin, Italy; 4. Division of Cardiac Surgery, University of Padua, Padua, Italy; 5. Centro Cardiologico Monzino, IRCCS, Milan, Italy; 6. Department of Cardiovascular Sciences and Community Health, University of Milan, Milan, Italy; 7. Division of Interventional Cardiology, Cardio-Thoracic-Vascular Department, San Raffaele Scientific Institute, Milan, Italy; 8. Division of Cardiology, Department of Medicine, University of Verona, Verona, Italy; 9. Department of Cardiac, Thoracic and Vascular Sciences, University of Padua, Padua, Italy
\end{abstract}

U. Benedetto and M. Bianco contributed equally to this manuscript.

This paper also includes supplementary data published online at: http://www.pcronline.com/eurointervention/127th_issue/223

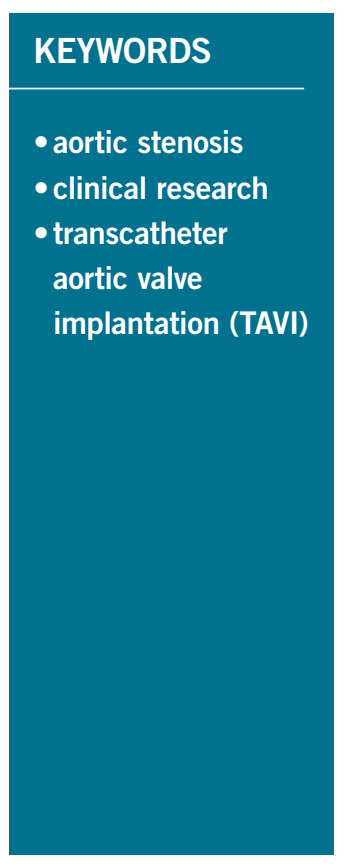

\begin{abstract}
Aims: The safety and efficacy of single vs. dual antiplatelet therapy (DAPT) in patients undergoing TAVI remain to be addressed. The aim of our study was to evaluate the usefulness of a DAPT compared to a single platelet therapy in patients undergoing TAVI with a balloon-expandable prosthesis.
\end{abstract}

Methods and results: All consecutive patients enrolled in the ITER registry were included. Patients undergoing TAVI discharged with aspirin alone were compared to those taking DAPT before and after selection using propensity score with matching. Subgroup analysis was performed for those on OAT. Prosthetic heart valve dysfunction at follow-up was the primary endpoint, whereas all-cause death, cardiovascular death, bleedings, vascular complications and cerebrovascular accidents were the secondary ones. From 1,364 patients, after propensity score with matching, 605 were selected for each group (aspirin alone vs. DAPT). At 30 days, rates of VARC mortality were lower in patients with aspirin alone $(1.5 \%$ vs. $4.1 \%$, $\mathrm{p}=0.003)$, mainly driven by a reduction of major vascular complications $(5.3 \%$ vs. $10.7 \%, \mathrm{p}<0.001)$ and of major bleedings ( $6.6 \%$ vs. $11.5 \%, \mathrm{p}<0.001)$, without a difference in prosthetic heart valve dysfunction after $45 \pm 14$ months ( $2.8 \%$ vs. $3.0 \%, \mathrm{p}=0.50)$. These results were confirmed on multivariable analysis.

Conclusions: After TAVI with a balloon-expandable prosthesis, aspirin alone does not increase the risk of prosthetic valve dysfunction, and reduces the risk of periprocedural complications and of 30-day all-cause death.

\footnotetext{
*Corresponding author: Dipartimento di Scienze Mediche, Divisione di Cardiologia, Città della Salute e della Scienza, Corso Bramante88/90,10126 Turin, Italy.E-mail:fabrizio.dascenzo@gmail.com
} 


\section{Abbreviations}

$\begin{array}{ll}\text { ASA } & \text { aspirin } \\ \text { CAD } & \text { coronary artery disease } \\ \text { DAPT } & \text { dual antiplatelet therapy } \\ \text { IQR } & \text { interquartile range } \\ \text { OAT } & \text { oral anticoagulation } \\ \text { PS } & \text { propensity score } \\ \text { RCT } & \text { randomised controlled trial(s) } \\ \text { TAVI } & \text { transcatheter aortic valve implantation } \\ \text { TIA } & \text { transient ischaemic attack } \\ \text { VARC } & \text { Valve Academic Research Consortium }\end{array}$

\section{Introduction}

Aortic valve replacement is the first-line therapy for patients with symptomatic aortic valve stenosis ${ }^{1-4}$. In recent years, transcatheter aortic valve implantation (TAVI) has emerged as the first choice for high-risk patients not suitable for a conventional aortic valve replacement ${ }^{5-10}$. The optimal peri-TAVI management of antithrombotic therapy represents one of the most relevant issues for these patients. Current guidelines recommend dual antiplatelet therapy with low-dose aspirin (ASA) and clopidogrel $75 \mathrm{mg} /$ day for the first six months, followed by ASA lifelong ${ }^{11,12}$. Unfortunately, the strength of this recommendation is weak and mainly based on expert consensus; heterogeneity among centres in the management of antiplatelet therapy is present. Actually, due to their high-risk features, these patients are frequently exposed to periprocedural bleedings, with an ominous impact on progno$\operatorname{sis}^{13}$. At the same time, most of the indications for an antiplatelet/ anticoagulation regimen after surgical biological valve implantation have come from consensus conference mainly based on investigational data from patients with mechanical valves ${ }^{14,15}$.

Regarding TAVI, a recent meta-analysis from Hassel et $\mathrm{al}^{16}$ on about 600 patients showed a trend towards less life-threatening and major bleeding without an increase of thromboembolic events, although this was limited by the small sample size of patients.

Consequently, we analysed the data from ITER ${ }^{17}$, an "allcomers", real-world, independent, multicentre registry including 1,656 patients treated with a balloon-expandable prosthesis, to identify the optimal management of antiplatelet therapy, evaluating the safety and efficacy of single vs. dual antiplatelet therapy (DAPT). The working hypothesis of our study was that the increase in bleeding and vascular access complications observed with DAPT exceeds the potential reduction of prosthetic heart valve dysfunction and TIA/stroke which may be obtained with aspirin and clopidogrel.

Finally, we also performed a dedicated analysis of patients with an indication for oral anticoagulation therapy (OAT).

\section{Methods}

The ITER registry includes 33 Italian centres performing balloon-expandable TAVI, taking into account virtually the entire national experience. Our study, based on the ITER registry, is a retrospective analysis of prospectively collected data. All patients undergoing balloon-expandable TAVI at each centre between 2007 and
2012 were enrolled in this registry. Ethics committees approved data collection and patient informed consent was always collected. As this is a real-world all-comers experience, patient selection and procedure strategy were carried out according to the policies, experience and protocols of the individual sites. All procedures were performed using Edwards SAPIEN and SAPIEN XT prostheses (Edwards Lifesciences, Irvine, CA, USA) with a retrograde or antegrade approach. Patients were stratified according to therapy at discharge: - Aspirin alone vs. aspirin and clopidogrel for at least six months.

- Aspirin and OAT with vitamin K antagonists vs. OAT with vita$\min \mathrm{K}$ antagonists alone.

\section{DATA AND DEFINITIONS}

Preoperative risk factors were defined according to the EuroSCORE (ES) classification. Presence of preoperative coronary artery disease was considered according to STS score definitions. Postoperative outcomes were defined according to the updated Valve Academic Research Consortium (VARC-2) definitions ${ }^{18}$.

\section{ENDPOINTS}

Prosthetic heart valve dysfunction at follow-up (defined as diagnosis of an aortic valve less than $1.2 \mathrm{~cm}^{2}$, an increase of medium gradient of more than $20 \mathrm{mmHg}$ and a peak velocity of more than $3 \mathrm{~m} / \mathrm{sec}$, excluding aortic valve regurgitation) was the primary endpoint, while all-cause death, cardiovascular death, bleedings, vascular complications and cerebrovascular accidents at 30 days and at follow-up were the secondary ones ${ }^{19}$. All the endpoints were adjudicated according to VARC-2 definitions ${ }^{18}$. Major bleedings at followup were defined as those needing hospitalisation and/or transfusion.

\section{FOLLOW-UP}

Patients underwent clinical and echocardiographic assessment at the study site before the operation, at hospital discharge, and then according to each centre's protocol. Follow-up time points were requested at three to six months, at one year and every year thereafter.

\section{STATISTICAL ANALYSIS}

Continuous variables are presented as means \pm standard deviation or median with the interquartile range (IQR). Categorical variables are presented as frequency (\%). Categorical variables were compared with Fisher's exact test. Parametric distribution of continuous variables was tested graphically and with the Kolmogorov-Smirnov test, and the appropriate analyses were used in accordance with the results. Multiple imputation using a bootstrapping-based expectation-maximisation algorithm was used to obtain three imputed data sets (http://www.jstatsoft.org/v45/i07/). Rubin's method was used to combine the results from each of the imputed data sets (Amelia R package). Due to lack of randomisation with regard to DAPT administration following TAVI, a propensity score (PS) was generated for each patient from a multivariable logistic regression model based on pre-treatment covariates as independent variables, with DAPT versus aspirin only administration as a binary dependent variable. Pairs of patients were derived using greedy 1:1 matching with a calliper 
width of 0.2 standard deviation of the logit of the PS (http:/CRAN. Rproject.org/package $=$ nonrandom $)^{20}$. The quality of the match was assessed by comparing selected pre-treatment variables in propensity score-matched patients using the standardised mean difference (SMD), for which an absolute standardised difference of greater than $20 \%$ is suggested to represent meaningful covariate imbalance. A Cox regression model, stratified on the matched pairs and adjusted for other medications at discharge, was used to estimate the treatment effect (i.e., DAPT vs. aspirin only) on outcomes of interest. This approach accounts for the within-pair homogeneity by allowing the baseline hazard function to vary across matched sets (http:// CRAN.R-project.org/package=survival). The Schoenfeld residuals test was used to test the independence between residuals and time and hence to test the proportional hazards assumption in Cox models (all p-values were $>0.05$ ). All p-values $<0.05$ were considered to indicate statistical significance. All statistical analyses were performed using R Statistical Software, version 3.2.3 (R Foundation for Statistical Computing, Vienna, Austria).

Moreover, logistic regression was performed to assess the impact of therapy on in-hospital major bleedings, while Cox multivariate analysis was performed for valve dysfunction. All statistical analyses were performed with SPSS Version 21 (IBM Corp., Armonk, NY, USA), and differences were considered significant at $\alpha=0.05$.

\section{Results}

\section{TOTAL STUDY COHORT}

One thousand six hundred and fifty-six $(1,656)$ patients were included, being 1,364 not on OAT ( 605 on aspirin and 759 on dual antiplatelet therapy), and 292 on OAT (131 on OAT and 161 on OAT and aspirin).

\section{TOTAL STUDY COHORT WITHOUT PATIENTS ON OAT}

Six hundred and five patients treated with aspirin and 759 with DAPT were enrolled (Figure 1). Baseline clinical risk factors differed significantly between the groups. Patients treated with DAPT were less frequently female ( $64 \%$ vs. $58 \%, \mathrm{p}=0.03)$, with higher rates of hypertension $(77 \%$ vs. $84 \%, \mathrm{p}=0.02)$, of previous myocardial infarction $(13 \%$ vs. $18 \%, \mathrm{p}=0.03)$, of peripheral artery disease $(33 \%$ vs.
$37 \% \mathrm{p}=0.04)$, of neurological dysfunction ( $7 \%$ vs. $10 \% \mathrm{p}=0.04)$, and of atrial fibrillation $(10 \%$ vs. $17 \%, \mathrm{p}<0.001)$. DAPT patients were more likely to be treated with valvuloplasty before TAVI (7\% vs. $12 \%, \mathrm{p}=0.03)$, and with transfemoral access ( $63 \%$ vs. $74 \%, \mathrm{p}<0.001)$.

At 30 days, all-cause mortality was lower in patients treated with aspirin alone $(1.5 \%$ vs. $4.1 \%, \mathrm{p}=0.003)$, mainly due to reduced risk of major vascular complications (5.3\% vs. $10.7 \%$, $\mathrm{p}<0.001)$, and of major bleedings $(6.6 \%$ vs. $11.5 \%, \mathrm{p}<0.001)$, and without increased risk of stroke $(1.5 \%$ vs. $1.3 \%, \mathrm{p}=0.59)$.

After a median follow-up of $45.0 \pm 14$ months, prosthetic valve dysfunction did not differ $(2.8 \%$ vs. $3.0 \%, \mathrm{p}=0.47)$, likewise allcause mortality $(26 \%$ vs. $27 \%, 0.48)$ and the risk of stroke and transient ischaemic attack (TIA) $(0.7 \%$ vs. $1.6 \%, \mathrm{p}=0.92)$, although with higher risk of major bleedings in the group of patients treated with DAPT (1.2\% vs. $3.6 \%, \mathrm{p}<0.001)$.

\section{MATCHED STUDY COHORT WITHOUT PATIENTS ON OAT AFTER PROPENSITY SCORE ANALYSIS}

After propensity score with matching analysis, 605 patients treated with aspirin and 605 treated with DAPT with similar clinical presentation, baseline risk factors and angiographic features were selected (Figure 1, Table 1). Therefore, the results of the initial study on the overall population were reproducible. In fact, at 30-day follow-up, rates of death were higher in the DAPT group (1.5\% vs. $4.5 \%$, p 0.002 ), due to a higher risk of major and minor vascular complications (respectively, $5.3 \%$ vs. $12.3 \%$ and $4.6 \%$ vs. $7.9 \%, \mathrm{p}<0.001$ ) and of major and minor bleedings (respectively, $6.7 \%$ vs. $12.3 \%$ and $2.0 \%$ vs. $7.3 \%, \mathrm{p}<0.001$ ). Risk of life-threatening bleedings and of stroke did not differ between groups (respectively, $7.6 \%$ vs. $9.8 \%$, $\mathrm{p}=0.65$, and $1.6 \%$ vs. $1.8 \%, \mathrm{p}=0.58$ ) (Figure $2 \mathrm{~A}$ ).

At follow-up, the risk of prosthetic heart dysfunction did not differ between the two groups $(2.8 \%$ vs. $3.0 \%, \mathrm{p}=0.50)$, nor did that of all-cause death $(26 \%$ vs. $27 \%, \mathrm{p}=0.69)$ or of stroke/TIA $(0.7 \%$ vs. $1.5 \%, \mathrm{p}=0.13)$, while patients on DAPT were more likely to experience major bleedings ( $1.6 \%$ vs. $4.0 \%, \mathrm{p}<0.001)$ (Figure 2B). The logistic regression and the Cox multivariate analysis confirmed the present results (Table 2, Table 3).

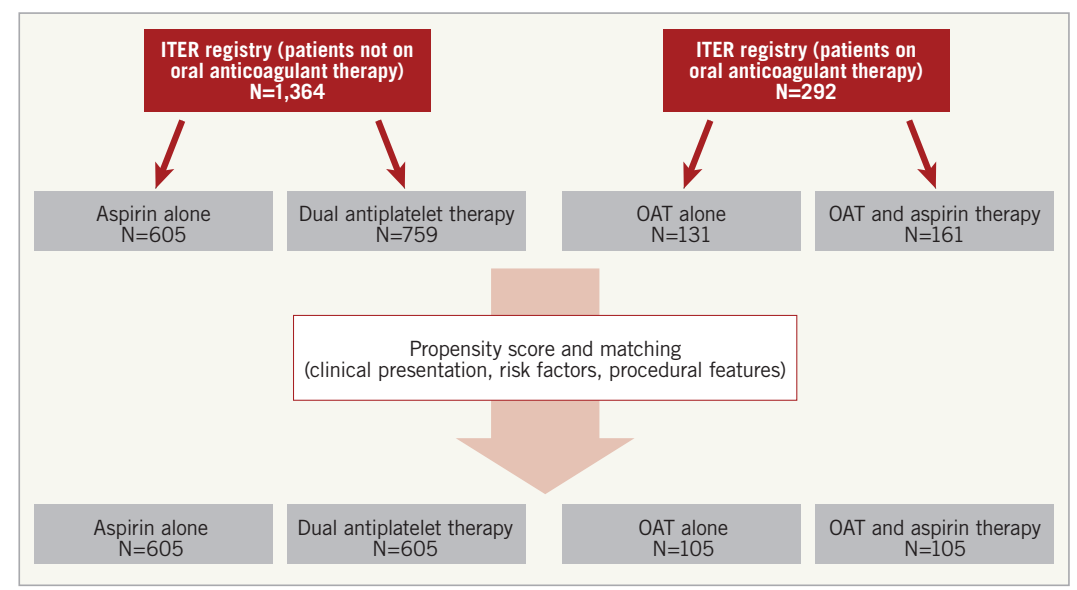

Figure 1. Selection for propensity score and matching analysis between patients on and not on OAT. 
Table 1. Baseline and interventional features of patients according to antiplatelet/anticoagulation regimen after propensity score with matching.

\begin{tabular}{|c|c|c|c|c|c|c|c|}
\hline & & $\begin{array}{l}\text { Aspirin only } \\
\text { (605: } 50 \%)\end{array}$ & $\begin{array}{c}\text { Dual antiplatelet } \\
\text { therapy } \\
(605: 50 \%)\end{array}$ & $p$-value & $\begin{array}{l}\text { OAT alone } \\
(105: 50 \%)\end{array}$ & $\begin{array}{c}\text { OAT and } \\
\text { aspirin } \\
(105: 50 \%)\end{array}$ & p-value \\
\hline \multicolumn{2}{|l|}{ Age (years) } & $81 \pm 4$ & $81 \pm 5$ & 0.43 & $81 \pm 5$ & $82 \pm 6$ & 0.43 \\
\hline \multicolumn{2}{|c|}{ Body mass index $\left(\mathrm{kg} / \mathrm{m}^{2}\right)$} & $26 \pm 6$ & $25 \pm 7$ & 0.54 & $26 \pm 5$ & $25 \pm 4$ & 0.54 \\
\hline \multicolumn{2}{|c|}{ Female gender (\%) } & $349(63)$ & $336(62)$ & 0.55 & $61(58)$ & $59(61)$ & 0.26 \\
\hline \multicolumn{2}{|l|}{ Diabetes mellitus (\%) } & $154(26)$ & $159(26)$ & 0.59 & $26(24)$ & $35(33)$ & 0.12 \\
\hline \multicolumn{2}{|l|}{ Hypertension (\%) } & $495(82)$ & $467(77)$ & 0.50 & $86(82)$ & $83(81)$ & 0.81 \\
\hline \multirow{2}{*}{$\begin{array}{l}\text { Previous myocardial } \\
\text { infarction (\%) }\end{array}$} & $<90$ days & $24(4)$ & $31(6)$ & \multirow{2}{*}{0.17} & $3(3)$ & $4(4)$ & \multirow{2}{*}{0.89} \\
\hline & $>90$ days & $79(14)$ & $87(15)$ & & $10(10)$ & $11(11)$ & \\
\hline \multicolumn{2}{|c|}{ Previous coronary artery disease (\%) } & $224(40)$ & $226(41)$ & 0.48 & $23(24)$ & $22(24)$ & 0.45 \\
\hline \multicolumn{2}{|c|}{ Peripheral vascular disease (\%) } & $197(37)$ & $193(36)$ & 0.34 & $38(38)$ & $41(41)$ & 0.11 \\
\hline \multicolumn{2}{|c|}{ Chronic obstructive pulmonary disease* (\%) } & $147(24)$ & $141(23)$ & 0.68 & $45(43)$ & $45(43)$ & 0.42 \\
\hline \multicolumn{2}{|c|}{ Neurological dysfunction* (\%) } & $45(7)$ & $49(8)$ & 0.67 & $29(27)$ & $31(29)$ & 0.65 \\
\hline \multirow[t]{2}{*}{ Ejection fraction } & $\%$ & $51 \pm 9$ & $52 \pm 12$ & 0.38 & $51 \pm 12$ & $52 \pm 12$ & 0.38 \\
\hline & less than $30 \%(\%)$ & $19(3)$ & $25(5)$ & 0.22 & $6(6)$ & $5(5)$ & 0.51 \\
\hline \multirow[t]{3}{*}{ Renal function } & dialysis & $16(3)$ & $18(4)$ & 0.44 & $4(4)$ & $4(4)$ & 0.49 \\
\hline & creatinine (mg/dl) & $1.2 \pm 0.6$ & $1.2 \pm 0.7$ & 0.78 & $1.2 \pm 0.6$ & $1.2 \pm 0.7$ & 0.78 \\
\hline & clearance & $48 \pm 22$ & $47 \pm 20$ & 0.06 & $48 \pm 22$ & $47 \pm 20$ & 0.06 \\
\hline \multicolumn{2}{|c|}{ Preoperative haemoglobin (g/dl) } & $11 \pm 1$ & $11 \pm 1$ & 0.65 & $12 \pm 1$ & $12 \pm 1$ & 0.65 \\
\hline \multicolumn{2}{|c|}{ Atrial fibrillation before TAVI (\%) } & $54(10)$ & $75(12)$ & 0.67 & $60(60)$ & $65(63)$ & 0.12 \\
\hline \multirow[t]{3}{*}{ Operative risk } & STS & $8 \pm 6$ & $8 \pm 7$ & 0.63 & $9 \pm 8$ & $9 \pm 6$ & 0.45 \\
\hline & EuroSCORE I & $19 \pm 13$ & $21 \pm 14$ & 0.91 & $22 \pm 12$ & $21 \pm 12$ & 0.31 \\
\hline & EuroSCORE II & $6 \pm 5$ & $7 \pm 6$ & 0.45 & $7 \pm 8$ & $7 \pm 4$ & 0.68 \\
\hline \multicolumn{2}{|c|}{ Valvuloplasty as bridge to TAVI } & $42(8)$ & $55(9)$ & 0.43 & $14(14)$ & $10(10)$ & 0.63 \\
\hline \multirow[t]{4}{*}{ Access } & transfemoral & $379(63)$ & $409(68)$ & \multirow{4}{*}{0.87} & $55(51)$ & $59(50)$ & \multirow{4}{*}{0.99} \\
\hline & transapical & $190(34)$ & $184(33)$ & & $46(46)$ & $45(47)$ & \\
\hline & transaortic & $6(1)$ & $5(0.9)$ & & $4(1)$ & $1(1)$ & \\
\hline & trans-subclavian & $1(0.2)$ & $1(0.2)$ & & & & \\
\hline \multirow[t]{2}{*}{ Kind of device (\%): } & SAPIEN & $181(33)$ & $183(33)$ & \multirow{2}{*}{0.47} & 35 (39) & 37 (38) & \multirow{2}{*}{0.31} \\
\hline & SAPIEN XT & $374(67)$ & $372(68)$ & & $70(61)$ & $68(62)$ & \\
\hline
\end{tabular}

Table 2. Results of the logistic regression for in-hospital major bleedings.

\begin{tabular}{|l|c|c|c|c|}
\hline & OR & LCI & UCI & p-value \\
\hline Patients not on OAT (aspirin or dual antiplatelet therapy) \\
\hline Female gender & 1.4 & 1.1 & 1.7 & 0.04 \\
\hline Diabetes mellitus & 0.9 & 0.6 & 1.3 & 0.67 \\
\hline AOCP & 1.1 & 0.7 & 1.9 & 0.98 \\
\hline Creatinine more than 2 mg/dl & 1.9 & 1.2 & 3.1 & 0.004 \\
\hline Previous MI & 0.9 & 0.7 & 1.5 & 0.21 \\
\hline Dual antiplatelet therapy & 1.9 & 1.4 & 2.6 & $<0.001$ \\
\hline Patients on OAT (OAT alone or $\mathbf{0 A T}$ and aspirin) \\
\hline Female gender & 0.8 & 0.2 & 8.1 & 0.67 \\
\hline Diabetes mellitus & 1.9 & 1.4 & 6.7 & 0.04 \\
\hline AOCP & 0.9 & 0.7 & 3.4 & 0.54 \\
\hline Creatinine more than 2 mg/dl & 1.6 & 1.4 & 5.6 & 0.004 \\
\hline Previous MI & 0.9 & 0.7 & 3.4 & 0.78 \\
\hline OAT and aspirin & 1.6 & 0.9 & 5.4 & 0.04 \\
\hline AOCP: ateral occls
\end{tabular}

AOCP: arterial occlusive critical pathology; LCl: lower confidence interval; OAT: oral anticoagulation therapy; UCI: upper confidence interval

\section{TOTAL STUDY COHORT WITH PATIENTS ON OAT}

One hundred and thirty-one patients treated with OAT and 161 with OAT and aspirin were enrolled (Figure 1).

Patients discharged with aspirin and OAT were less frequently female ( $64 \%$ vs. $54 \%$, $p=0.07)$, presented with higher rates of coronary artery disease $(25 \%$ vs. $39 \%, \mathrm{p}=0.01)$ and were treated more frequently with the transfemoral approach $(41 \%$ vs. $66 \%, \mathrm{p}<0.001)$.

Table 3. Results of Cox multivariate analysis for valve dysfunction at follow-up.

\begin{tabular}{|c|c|c|c|c|}
\hline & HR & LCI & UCI & $p$-value \\
\hline \multicolumn{5}{|c|}{$\begin{array}{l}\text { Patients not on OAT (aspirin or dual antiplatelet therapy) not on } \\
\text { oral anticoagulant }\end{array}$} \\
\hline Prosthesis diameter (mm) & 0.7 & 0.4 & 8.7 & 0.89 \\
\hline Valvuloplasty as bridge to TAVI & 0.7 & 0.4 & 8.2 & 0.53 \\
\hline Porcelain aorta & 1.4 & 0.2 & 5.2 & 0.42 \\
\hline OAT and aspirin & 1.9 & 0.2 & 5.6 & 0.21 \\
\hline
\end{tabular}




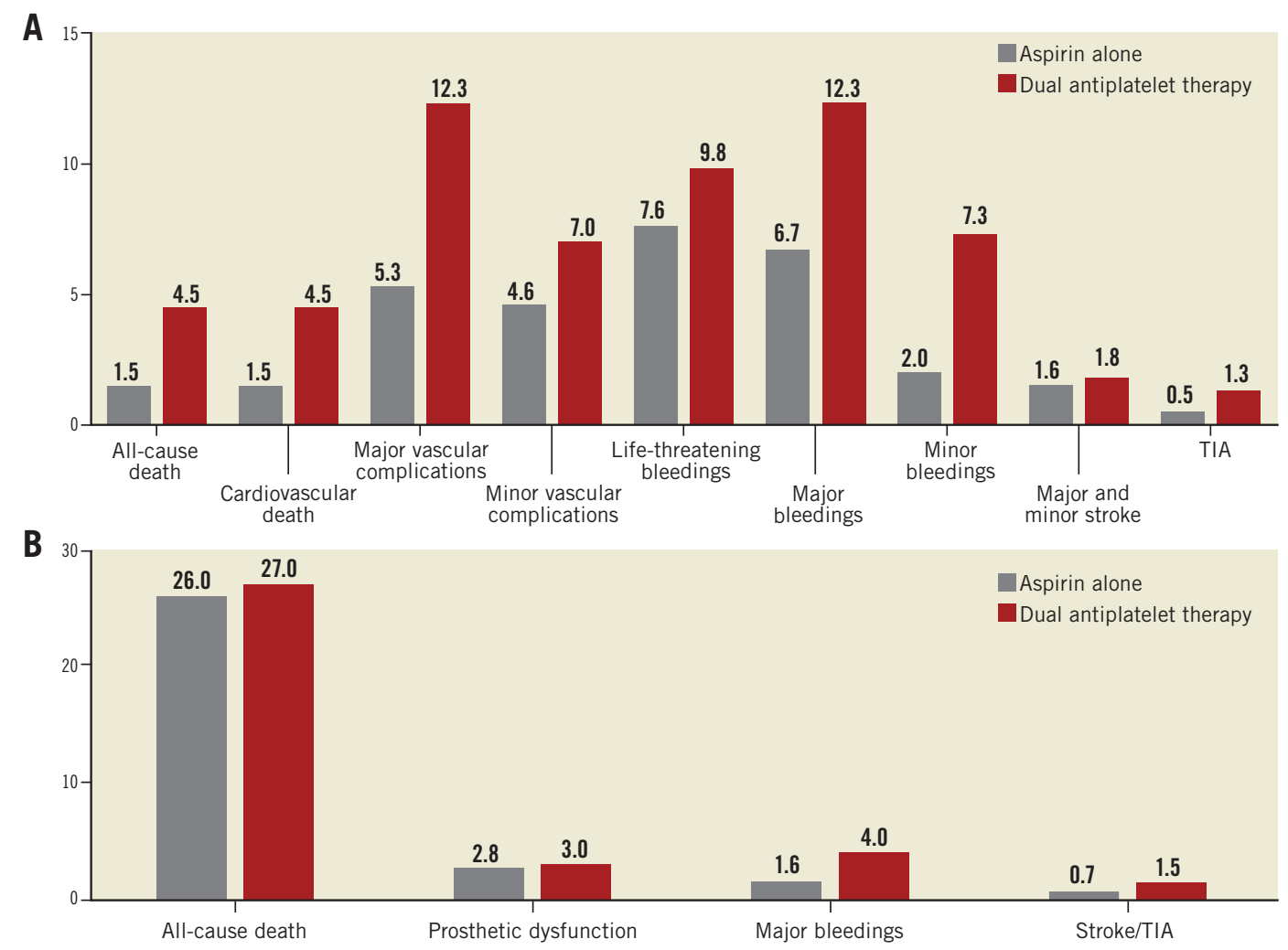

Figure 2. Patients not on anticoagulant therapy. A) Thirty-day and B) long-term outcomes after propensity score and matching analysis.

For 30-day outcomes, all-cause mortality did not differ $(3.8 \%$ vs. $3.4 \%, \mathrm{p}=0.61)$, despite higher risk of minor vascular complications $(4 \%$ vs. $11 \%, \mathrm{p}=0.04)$ and of life-threatening bleedings in patients treated with OAT plus aspirin ( $4 \%$ vs. $9 \%, \mathrm{p}=0.03)$.

After a median follow-up of $45.0 \pm 14$ months, similar rates of prosthetic valve dysfunction $(2.0 \%$ vs. $2.0 \%, \mathrm{p}=0.56)$, of all-cause mortality ( $37 \%$ vs. $32 \%, \mathrm{p}=0.22)$ and of stroke and TIA ( $4.0 \%$ vs. $3.0 \%, \mathrm{p}=0.45$ ) were reported, but with increased risk of major bleedings in patients treated with OAT and aspirin $(2 \%$ vs. $4 \%, \mathrm{p}<0.0)$.

\section{MATCHED STUDY COHORT FOR PATIENTS WITH OAT AFTER PROPENSITY SCORE ANALYSIS}

After propensity score with matching analysis, 105 patients from each group were included, with well-balanced baseline and procedural features (Table 1). At 30-day follow-up, rates of all-cause death were lower in the OAT alone group, despite being not significant $(2.9 \%$ vs. $5.7 \%, \mathrm{p}=0.44$ ), with a higher risk of life-threatening bleedings and minor vascular complications with OAT and aspirin (Figure 3A).

At follow-up, the risk of prosthetic heart dysfunction did not differ between the two groups ( $2.9 \%$ vs. $2.9 \%, \mathrm{p}=0.65)$, with a higher but not significant risk of major bleedings for patients treated with OAT plus aspirin $(2.9 \%$ vs. $4.8 \%, \mathrm{p}=0.36)$ and a similar rate of stroke/TIA $(2.9 \%$ vs. $3.8 \%, p=0.50)$ (Figure 3B). The logistic regression and the Cox multivariate analysis confirmed the present results (Table 2).

Finally, a summary of the main findings of our study is presented in Table 4.
Table 4. Summary of the main results of the study in patients treated with antiplatelet/anticoagulation therapy.

\begin{tabular}{|c|c|c|c|}
\hline & $\begin{array}{l}\text { Aspirin only } \\
(\mathrm{N}=605)(\%)\end{array}$ & $\begin{array}{c}\text { DAPT } \\
(\mathrm{N}=605)(\%)\end{array}$ & $p$-value \\
\hline \multicolumn{4}{|l|}{ 30-day follow-up } \\
\hline All-cause death & 1.5 & 4.5 & 0.002 \\
\hline Major vascular complication & 5.3 & 12.3 & $<0.001$ \\
\hline Minor vascular complication & 4.6 & 7.9 & $<0.001$ \\
\hline Major bleeding & 6.7 & 12.3 & $<0.001$ \\
\hline Minor bleeding & 2.0 & 7.3 & $<0.001$ \\
\hline Life-threatening bleeding & 7.6 & 9.8 & 0.65 \\
\hline Stroke & 1.6 & 1.8 & 0.58 \\
\hline \multicolumn{4}{|l|}{ Long-term follow-up } \\
\hline Prosthetic heart valve dysfunction & 2.8 & 3.0 & 0.50 \\
\hline All-cause death & 26.0 & 27.0 & 0.69 \\
\hline Major bleeding & 1.4 & 4.0 & $<0.001$ \\
\hline \multirow[t]{2}{*}{ Stroke/TIA } & 0.7 & 1.5 & 0.13 \\
\hline & $\begin{array}{c}\text { OAT only } \\
(N=105)(\%)\end{array}$ & $\begin{array}{c}\text { OAT and aspirin } \\
(\mathrm{N}=105)(\%)\end{array}$ & $p$-value \\
\hline \multicolumn{4}{|l|}{ 30-day follow-up } \\
\hline All-cause death & 2.9 & 5.7 & 0.44 \\
\hline Life-threatening bleeding & 4.8 & 11.4 & $<0.001$ \\
\hline \multicolumn{4}{|l|}{ Long-term follow-up } \\
\hline Prosthetic heart valve dysfunction & 2.9 & 2.9 & 0.65 \\
\hline Major bleeding & 2.9 & 4.8 & 0.36 \\
\hline Stroke/TIA & 2.9 & 3.8 & 0.50 \\
\hline
\end{tabular}



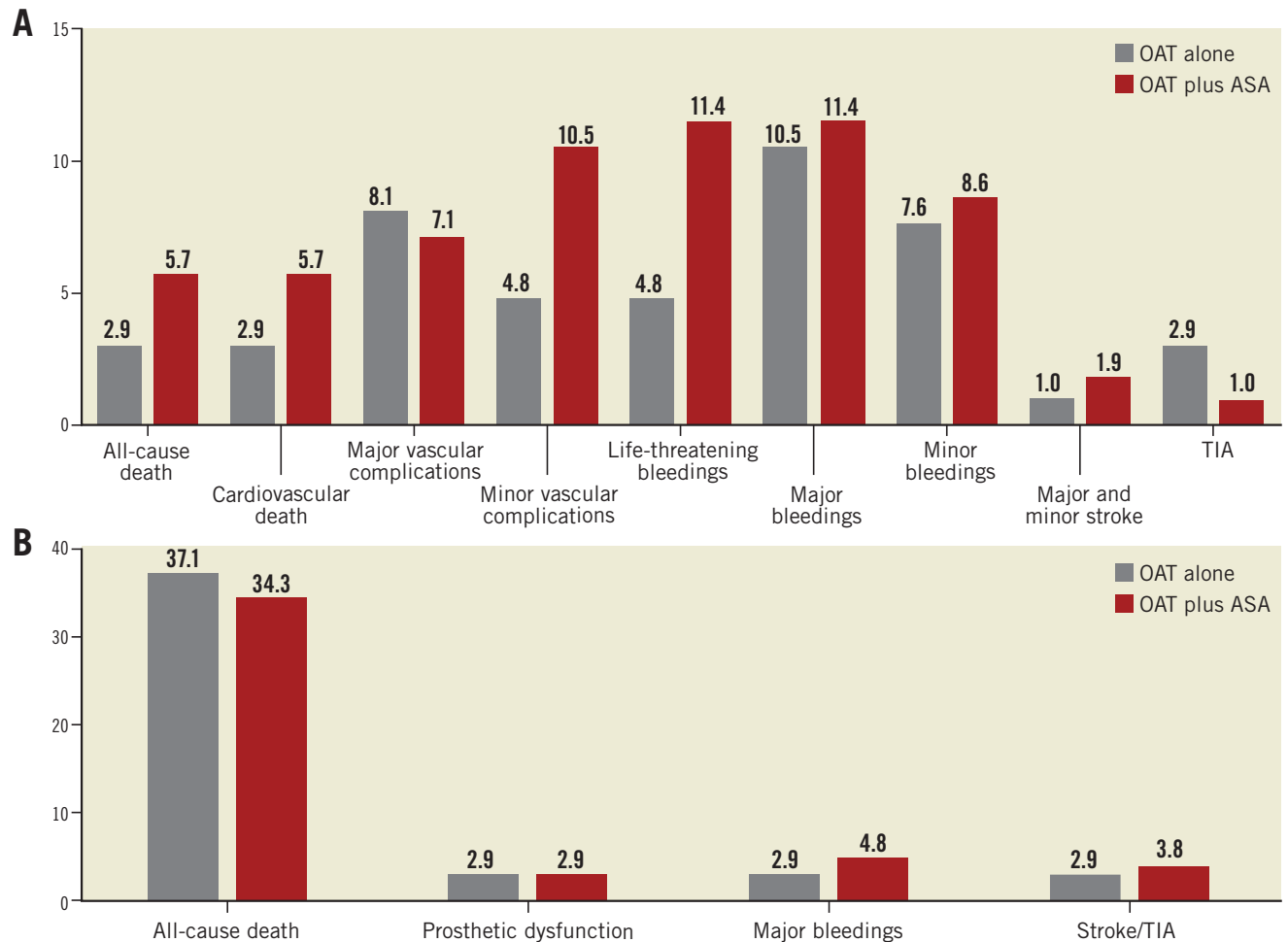

Figure 3. Patients on anticoagulant therapy. A) Thirty-day and B) long-term outcomes after propensity score and matching analysis.

\section{Discussion}

The main findings of our work are: 1) aspirin monotherapy does not increase the risk of prosthetic valve dysfunction, and reduces the risk of 30-day major vascular complications and bleedings which were confirmed to be independent predictors of 30-day allcause mortality; 2) aspirin monotherapy reduces the rate of 30-day mortality; and 3) patients treated with OAT plus aspirin show a similar risk of valve dysfunction, with higher risk of bleedings at 30 days compared to patients treated with OAT alone.

The optimal management of antiplatelet therapy in patients who have undergone TAVI is still a matter of debate ${ }^{16,21-23}$. Only two small randomised controlled trials (RCT) have compared aspirin monotherapy with DAPT for three to six months after TAVI. They both found no difference in terms of safety and efficacy between the two study arms but a significant increase in the incidence of major bleedings in patients treated with DAPT ${ }^{21,22}$. These data were recently endorsed by a meta-analysis from Hassel et al on about 600 patients that showed a trend towards less life-threatening and major bleeding without an increase of ACS, strokes and mortality in patients treated with aspirin monotherapy ${ }^{16}$, as did a recent prospective study performed on about 500 patients $^{23}$. Our study performed on more than 1,000 patients confirms these findings and shows that late valve dysfunction, all-cause mortality and stroke are unrelated to the antiplatelet therapy, as suggested by previous European registries ${ }^{24,25}$.

Patients treated with DAPT peri-TAVI are at increased risk of major bleeding. Often DAPT is mandatory because patients are affected by concomitant coronary artery disease $(\mathrm{CAD})^{26}$, but the increased risk of bleeding is present also in patients without CAD. The patients who undergo TAVI are usually elderly, with many comorbidities, a low ejection fraction and with higher incidence of chronic kidney disease. All of these factors contribute to an increase in the risk of bleeding ${ }^{27}$. Our study, showing comparable efficacy endpoints and lower incidence of bleedings in patients treated only with ASA, suggests re-evaluating the guideline recommendations on antiplatelet therapy, at least in those patients without compelling indications to DAPT such as CAD with a recent revascularisation. This statement is reinforced by the finding of increased 30-day mortality in patients treated with DAPT. Such mortality is reduced in those who were treated with aspirin alone and is mainly attributable to the increased incidence of major bleeding. The latter is responsible for an increase in deaths, especially in frail patients such as those who undergo TAVI ${ }^{13,28}$.

The original idea of using DAPT therapy in patients undergoing biological valve implantation stems from three practical problems: 1) the high incidence of thrombocytopaenia observed after the first procedures that were performed with extracorporeal circulation $^{29}, 2$ ) the time needed for prosthesis endothelialisation, and 3) the need to reduce the incidence of thromboembolism. The advances in valve design and technical improvement in deployment no longer require the use of extracorporeal circulation, removing one potential source of platelet activation ${ }^{30}$. Moreover, the SAPIEN ${ }^{\circledR}$ and SAPIEN XT ${ }^{\circledR}$ are biological prosthetic valves made of bovine pericardial tissue and, despite the fact that complete endothelialisation is probably reached in about three months ${ }^{31}$, their thrombogenicity seems to be very low, as 
already demonstrated by a large European registry ${ }^{24}$. The ITER registry confirms this datum and does not show a difference in thrombotic events between patients treated with ASA and those treated with DAPT. This further weakens the evidence in favour of DAPT in patients undergoing TAVI.

\section{Limitations}

The present study has many limitations. First, it has a retrospective design, despite being performed in high-volume centres and with high quality both for TAVI and for research. Second, the propensity score may allow adjustment of known confounders, but not for those not recorded, differently from RCTs. Third, the primary endpoint is an infrequent event, and consequently, despite well balanced results from propensity score (Supplementary Appendix, Supplementary Tables 1-4) the present analysis may be underpowered. Moreover, given the observational design, no sample size calculation was performed. Fourth, in our analysis we considered only two models of balloon-expandable valves; both of them are no longer used. However, our analysis is focused on the efficacy and safety of the use of a single antiplatelet therapy and, despite our results being not definitive because they are derived from retrospective data, we can assume that they can apply to new models of balloon-expandable biological prosthetic valves. Moreover, no data about the loading of clopidogrel were reported.

Finally, our results are mainly driven by the higher incidence of bleeding and vascular complications in the DAPT groups. Despite the fact that the use of smaller sheaths has significantly reduced the incidence of vascular complications, these are still the most common complications and have the most impact on prognosis in patients undergoing TAVI ${ }^{13,28}$. The use of a single antiplatelet agent could lead to a reduction of major bleeding from the access site, as suggested from our study.

\section{Conclusions}

After TAVI with a balloon-expandable prosthesis, aspirin alone seems not to increase the risk of prosthetic valve dysfunction, and seems to reduce the risk of periprocedural complications and of 30-day all-cause death. For patients needing OAT, oral anticoagulation alone reduces periprocedural complications with a similar safety profile to a combination with aspirin at follow-up. Our findings should be confirmed by a large randomised controlled trial before they can be recommended in everyday practice.

\section{Impact on daily practice}

Patients after TAVI are treated with DAPT for three or six months. This practice is mainly based on expert consensus. DAPT is affected by a higher number of bleedings if compared to single antiplatelet therapy. The results of our study show a lower incidence of bleeding without an increase in valvular dysfunction and procedural complications. If further studies with an RCT design confirm these data, peri-TAVI antiplatelet therapy management could change in favour of mono antiplatelet therapy.

\section{Appendix. ITER Investigators}

Alaide Chieffo, Ospedale San Raffaele, Milan, Italy; Gennaro Giustino, Ospedale San Raffaele, Milan, Italy; Tommaso Regesta, Divisione di Cardiochirurgia, IRCCS San Martino-IST, Genoa, Italy; Massimo Napodano, Department of Cardiac, Thoracic and Vascular Sciences - University of Padua, Padua, Italy; Davide Gabbieri, Hesperia Hospital, Modena, Italy; Francesco Saia, AOU di Bologna, Policlinico S. Orsola-Malpighi, Bologna, Italy; Corrado Tamburino, Ospedale Ferrarotto, Università di Catania, Catania, Italy; Diego Cugola, AO Papa Giovanni XXIII, Bergamo, Italy; Marco Aiello, IRCCS Policlinico S. Matteo, Pavia, Italy; Francesco Sanna, AO Brotzu, Cagliari, Italy; Alessandro Iadanza, AOU Policlinico Le Scotte, Siena, Italy; Esmeralda Pompei, AOUD Santa Maria della Misericordia, Udine, Italy; Pierluigi Stefàno, AOU Careggi, Florence, Italy; Antioco Cappai, Humanitas Research Hospital, Rozzano, Italy; Alessandro Minati, Ospedale Cattinara, Trieste, Italy; Mauro Cassese, Clinica S. Maria, Bari, Italy; Gian Luca Martinelli, Clinica S. Maria, Bari, Italy; Andrea Agostinelli, Ospedale Maggiore, Parma, Italy; Rosario Fiorilli, AO San Camillo Forlanini, Rome, Italy; Francesco Casilli, IRCCS Policlinico San Donato, Milan, Italy; Maurizio Reale, A.O. Cesare Biagio e Arrigo, Alessandria, Italy; Francesco Bedogni, Istituto Clinico Sant'Ambrogio, Milan, Italy; Anna Sonia Petronio, AOU Pisana, Pisa, Italy; Pierluigi Omedè, Dipartimento di Scienze Mediche, Divisione di Cardiologia, Città della Salute e della Scienza, Turin, Italy; Antonio Montefusco, Dipartimento di Scienze Mediche, Divisione di Cardiologia, Città della Salute e della Scienza, Turin, Italy; Rosa Alba Mozzillo, AOU Federico II, Naples, Italy; Roberto Bonmassari, Ospedale S. Chiara, Trento, Italy; Carlo Briguori, Clinica Mediterranea, Naples, Italy; Armando Liso, Città di Lecce Hospital, Lecce, Italy; Gennaro Sardella, Policlinico Umberto I, Rome, Italy; Giuseppe Bruschi, Ospedale Niguarda, Milan, Italy; Gino Gerosa, Department of Cardiac, Thoracic and Vascular Sciences - University of Padua, Padua, Italy; Mauro Rinaldi, Dipartimento di Scienze Mediche, Divisione di Cardiologia, Città della Salute e della Scienza, Turin, Italy; Francesco Romeo, Università degli Studi Tor Vergata, Rome, Italy.

\section{Conflict of interest statement}

F. D'Ascenzo was supported by a Società Italiana di Cardiologia (SIC) grant. The other authors have no conflicts of interest to declare.

\section{References}

1. Vahanian A, Alfieri O, Andreotti F, Antunes MJ, BarónEsquivias G, Baumgartner H, Borger MA, Carrel TP, De Bonis M, Evangelista A, Falk V, Iung B, Lancellotti P, Pierard L, Price S, Schäfers HJ, Schuler G, Stepinska J, Swedberg K, Takkenberg J, Von Oppell UO, Windecker S, Zamorano JL, Zembala M; Joint Task Force on the Management of Valvular Heart Disease of the European Society of Cardiology (ESC), European Association for Cardio-Thoracic Surgery (EACTS). Guidelines on the 
management of valvular heart disease (version 2012). Eur Heart J. 2012;33:2451-96.

2. Nkomo VT, Gardin JM, Skelton TN, Gottdiener JS, Scott CG, Enriquez-Sarano M. Burden of valvular heart diseases: a population-based study. Lancet. 2006;368:1005-11.

3. Osnabrugge RL, Mylotte D, Head SJ, Van Mieghem NM, Nkomo VT, LeReun CM, Bogers AJ, Piazza N, Kappetein AP. Aortic stenosis in the elderly: disease prevalence and number of candidates for transcatheter aortic valve replacement: a meta-analysis and modeling study. J Am Coll Cardiol. 2013;62:1002-12.

4. Nishimura RA, Otto CM, Bonow RO, Carabello BA, Erwin JP 3rd, Guyton RA, O'Gara PT, Ruiz CE, Skubas NJ, Sorajja P, Sundt TM 3rd, Thomas JD, Anderson JL, Halperin JL, Albert NM, Bozkurt B, Brindis RG, Creager MA, Curtis LH, DeMets D, Guyton RA, Hochman JS, Kovacs RJ, Ohman EM, Pressler SJ, Sellke FW, Shen WK, Stevenson WG, Yancy CW; American College of Cardiology, American College of Cardiology/American Heart Association; American Heart Association. 2014 AHA/ACC guideline for the management of patients with valvular heart disease: a report of the American College of Cardiology/American Heart Association Task Force on Practice Guidelines. J Thorac Cardiovasc Surg. 2014;148:e1-e132.

5. Cribier A, Eltchaninoff $\mathrm{H}$, Bash A, Borenstein N, Tron $\mathrm{C}$, Bauer F, Derumeaux G, Anselme F, Laborde F, Leon MB. Percutaneous transcatheter implantation of an aortic valve prosthesis for calcific aortic stenosis: first human case description. Circulation. 2002;106:3006-8.

6. Smith CR, Leon MB, Mack MJ, Miller DC, Moses JW, Svensson LG, Tuzcu EM, Webb JG, Fontana GP, Makkar RR, Williams M, Dewey T, Kapadia S, Babaliaros V, Thourani VH, Corso P, Pichard AD, Bavaria JE, Herrmann HC, Akin JJ, Anderson WN, Wang D, Pocock SJ; PARTNER Trial Investigators. Transcatheter versus surgical aortic-valve replacement in high-risk patients. N Engl J Med. 2011;364:2187-98.

7. Moretti C, D'Ascenzo F, Mennuni M, Taha S, Brambilla N, Nijhoff F, Fraccaro C, Barbanti M, Tamburino C, Tarantini G, Rossi ML, Presbitero P, Napodanno M, Stella P, Bedogni F, Omedè P, Conrotto F, Montefusco A, Giordana F, Biondi Zoccai G, Agostoni P, D'Amico M, Rinaldi M, Marra S, Gaita F. Meta-analysis of comparison between self-expandable and balloon-expandable valves for patients having transcatheter aortic valve implantation. Am J Cardiol. 2015;115:1720-5.

8. Wenaweser P, Stortecky S, Heg D, Tueller D, Nietlispach F, Falk V, Pedrazzini G, Jeger R, Reuthebuch O, Carrel T, Räber L, Amann FW, Ferrari E, Toggweiler S, Noble S, Roffi M, Gruenenfelder J, Jüni P, Windecker S, Huber C. Short-term clinical outcomes among patients undergoing transcatheter aortic valve implantation in Switzerland: the Swiss TAVI registry. EuroIntervention. 2014;10:982-9.

9. Conrotto F, D’Ascenzo F, Giordana F, Colaci C, Sacciatella P, Biondi-Zoccai G, Moretti C, D'Amico M, Gaita F, Marra S. Impact of access on TAVI procedural and midterm follow-up: a meta-analysis of 13 studies and 10,468 patients. J Interv Cardiol. 2014;27:500-8.
10. Linke A, Wenaweser P, Gerckens U, Tamburino C, Bosmans J, Bleiziffer S, Blackman D, Schäfer U, Müller R, Sievert H, Søndergaard L, Klugmann S, Hoffmann R, Tchétché D, Colombo A, Legrand VM, Bedogni F, lePrince P, Schuler G, Mazzitelli D, Eftychiou C, Frerker C, Boekstegers P, Windecker S, Mohr FW, Woitek F, Lange R, Bauernschmitt R, Brecker S; ADVANCE study Investigators. Treatment of aortic stenosis with a self-expanding transcatheter valve: the International Multi-centre ADVANCE Study. Eur Heart J. 2014;35:2672-84.

11. Conrotto F, D'Ascenzo F, Salizzoni S, Presbitero P, Agostoni P, Tamburino C, Tarantini G, Bedogni F, Nijhoff F, Gasparetto V, Napodano M, Ferrante G, Rossi ML, Stella P, Brambilla N, Barbanti M, Giordana F, Grasso C, Biondi Zoccai G, Moretti C, D'Amico M, Rinaldi M, Gaita F, Marra S. A gender based analysis of predictors of all cause death after transcatheter aortic valve implantation. Am J Cardiol. 2014;114:1269-74.

12. Webb J, Rodés-Cabau J, Fremes S, Pibarot P, Ruel M, Ibrahim R, Welsh R, Feindel C, Lichtenstein S. Transcatheter aortic valve implantation: a Canadian Cardiovascular Society position statement. Can J Cardiol. 2012;28:520-8.

13. Moretti C, D’Amico M, D'Ascenzo F, Colaci C, Salizzoni S, Tamburino C, Presbitero P, Marra S, Sheiban I, Gaita F. Impact on prognosis of periprocedural bleeding after TAVI: mid-term follow-up of a multicenter prospective study. J Interv Cardiol. 2014;27:293-9.

14. Little SH, Massel DR. Antiplatelet and anticoagulation for patients with prosthetic heart valves. Cochrane Database Syst Rev. 2003; CD003464.

15. Vahanian A, Baumgartner H, Bax J, Butchart E, Dion R, Filippatos G, Flachskampf F, Hall R, Iung B, Kasprzak J, Nataf P, Tornos P, Torracca L, Wenink A; Task Force on the Management of Valvular Hearth Disease of the European Society of Cardiology; ESC Committee for Practice Guidelines. Guidelines on the management of valvular heart disease: The Task Force on the Management of Valvular Heart Disease of the European Society of Cardiology. Eur Heart J. 2007;28:230-68.

16. Hassell ME, Hildick-Smith D, Durand E, Kikkert WJ, Wiegerinck EM, Stabile E, Ussia GP, Sharma S, Baan J Jr, Eltchaninoff H, Rubino P, Barbanti M, Tamburino C, Poliacikova P, Blanchard D, Piek JJ, Delewi R. Antiplatelet therapy following transcatheter aortic valve implantation. Heart. 2015;101:1118-25.

17. Salizzoni S, D’Onofrio A, Agrifoglio M, Colombo A, Chieffo A, Cioni M, Besola L, Regesta T, Rapetto F, Tarantini G, Napodano M, Gabbieri D, Saia F, Tamburino C, Ribichini F, Cugola D, Aiello M, Sanna F, Iadanza A, Pompei E, Stefàno P, Cappai A, Minati A, Cassese M, Martinelli G, Agostinelli A, Fiorilli R, Casilli F, Reale M, Bedogni F, Petronio A, Mozzillo R, Bonmassari R, Briguori C, Liso A, Sardella G, Bruschi G, Fiorina C, Filippini C, Moretti C, D'Amico M, La Torre M, Di Bartolomeo R, Gerosa G, Rinaldi M; TAVI Team. Early and mid-term outcomes of 1904 patients undergoing transcatheter balloon-expandable valve implantation in Italy: results from the Italian Transcatheter Balloon-Expandable Valve Implantation Registry (ITER). Eur J Cardiothorac Surg. 2016;50:1139-48. 
18. Kappetein AP, Head SJ, Généreux P, Piazza N, van Mieghem NM, Blackstone EH, Brott TG, Cohen DJ, Cutlip DE, van Es GA, Hahn RT, Kirtane AJ, Krucoff MW, Kodali S, Mack MJ, Mehran R, Rodés-Cabau J, Vranckx P, Webb JG, Windecker S, Serruys PW, Leon MB; Valve Academic Research Consortium (VARC)-2. Updated standardized endpoint definitions for transcatheter aortic valve implantation: the Valve Academic Research Consortium-2 consensus document (VARC-2). Eur J Cardiothorac Surg. 2012;42:S45-60.

19. Zoghbi WA, Enriquez-Sarano M, Foster E, Grayburn PA, Kraft CD, Levine RA, Nihoyannopoulos P, Otto CM, Quinones MA, Rakowski H, Stewart WJ, Waggoner A, Weissman NJ; American Society of Echocardiography. Recommendations for evaluation of the severity of native valvular regurgitation with two-dimensional and Doppler echocardiography. J Am Soc Echocardiogr. 2003;16: 777-802.

20. D’Ascenzo F, Cavallero E, Biondi-Zoccai G, Moretti C, Omede P, Bollati M, Castagno D, Modena MG, Gaita F, Sheiban I. Use and misuse of multivariable approaches in interventional cardiology studies on drug-eluting stents: a systematic review. J Interv Cardiol. 2012;25:611-21.

21. Ussia GP, Scarabelli M, Mulè M, Barbanti M, Sarkar K, Cammalleri V, Immè S, Aruta P, Pistritto AM, Gulino S, Deste W, Capodanno D, Tamburino C. Dual antiplatelet therapy versus aspirin alone in patients undergoing transcatheter aortic valve implantation. Am J Cardiol. 2011;108:1772-6.

22. Stabile E, Pucciarelli A, Cota L, Sorropago G, Tesorio T, Salemme L, Popusoi G, Ambrosini V, Cioppa A, Agrusta M, Catapano D, Moscariello C, Trimarco B, Esposito G, Rubino P. SAT-TAVI (single antiplatelet therapy for TAVI) study: a pilot randomized study comparing double to single antiplatelet therapy for transcatheter aortic valve implantation. Int J Cardiol. 2014; 174:624-7.

23. Durand E, Blanchard D, Chassaing S, Gilard M, Laskar M, Borz B, Lafont A, Barbey C, Godin M, Tron C, Zegdi R, Chatel D, Le Page O, Litzler PY, Bessou JP, Danchin N, Cribier A, Eltchaninoff $\mathrm{H}$. Comparison of two antiplatelet therapy strategies in patients undergoing transcatheter aortic valve implantation. Am J Cardiol. 2014;113:355-60.

24. Thomas M, Schymik G, Walther T, Himbert D, Lefèvre T, Treede H, Eggebrecht H, Rubino P, Colombo A, Lange R, Schwarz RR, Wendler O. One-year outcomes of cohort 1 in the Edwards SAPIEN Aortic Bioprosthesis European Outcome (SOURCE) registry: the European registry of transcatheter aortic valve implantation using the Edwards SAPIEN valve. Circulation. 2011;124:425-33.

25. Thomas M, Schymik G, Walther T, Himbert D, Lefèvre T, Treede H, Eggebrecht H, Rubino P, Michev I, Lange R, Anderson WN, Wendler O. Thirty-day results of the SAPIEN aortic Bioprosthesis European Outcome (SOURCE) Registry:
A European registry of transcatheter aortic valve implantation using the Edwards SAPIEN valve. Circulation. 2010;122:62-9.

26. Wenaweser P, Pilgrim T, Guerios E, Stortecky S, Huber C, Khattab AA, Kadner A, Buellesfeld L, Gloekler S, Meier B, Carrel T, Windecker S. Impact of coronary artery disease and percutaneous coronary intervention on outcomes in patients with severe aortic stenosis undergoing transcatheter aortic valve implantation. EuroIntervention. 2011;7:541-8.

27. Manoukian SV. Predictors and impact of bleeding complications in percutaneous coronary intervention, acute coronary syndromes, and ST-segment elevation myocardial infarction. Am J Cardiol. 2009;104:9C-15C.

28. Pilgrim T, Stortecky S, Luterbacher F, Windecker S, Wenaweser P. Transcatheter aortic valve implantation and bleeding: incidence, predictors and prognosis. J Thromb Thrombolysis. 2013;35:456-62.

29. Grube E, Laborde JC, Gerckens U, Felderhoff T, Sauren B, Buellesfeld L, Mueller R, Menichelli M, Schmidt T, Zickmann B, Iversen S, Stone GW. Percutaneous implantation of the CoreValve self-expanding valve prosthesis in high-risk patients with aortic valve disease: the Siegburg first-in-man study. Circulation. 2006; 114:1616-24.

30. Ussia GP, Scarabelli M, Mulè M, Barbanti M, Cammalleri V, Immè S, Aruta P, Pistritto AM, Carbonaro A, Deste W, Sciuto P, Licciardello G, Calvi V, Tamburino C. Postprocedural management of patients after transcatheter aortic valve implantation procedure with self-expanding bioprosthesis. Catheter Cardiovasc Interv. 2010;76:757-66.

31. Noble S, Asgar A, Cartier R, Virmani R, Bonan R. Anatomopathological analysis after CoreValve Revalving system implantation. EuroIntervention. 2009;5:78-85.

\section{Supplementary data}

Supplementary Appendix. List of participating centres.

Supplementary Table 1. Standardised difference for baseline features of patients according to antiplatelet regimen before and after propensity score with matching.

Supplementary Table 2. Standardised difference for interventional features of patients according to antiplatelet regimen before and after propensity score with matching.

Supplementary Table 3. Standardised difference for baseline features of patients according to antiplatelet/anticoagulation regimen before propensity score with matching.

Supplementary Table 4. Standardised difference for interventional features of patients according to antiplatelet/anticoagulation regimen before propensity score with matching.

The supplementary data are published online at:

http://www.pcronline.com/

eurointervention/127th issue/223 


\section{Supplementary data}

Supplementary Appendix. List of participating centres.

\section{Leading study centre}

Dipartimento di Scienze Mediche, Divisione di Cardiologia, Città della Salute e della Scienza, Turin, Italy

\section{Participating study centres}

1. Dipartimento di Scienze Mediche, Divisione di Cardiologia, Città della Salute e della Scienza, Turin, Italy;

2. School of Clinical Sciences, University of Bristol and Bristol Royal Infirmary, Bristol, United Kingdom;

3. Department of Cardiac, Thoracic and Vascular Sciences - University of Padua, Padua, Italy;

4. Centro Cardiologico Monzino - Department of Clinical Sciences and Community, University of Milan, Milan, Italy;

5. Ospedale San Raffaele, Milan and EMO GVM Centro Cuore Columbus, Milan, Italy;

6. Divisione di Cardiochirurgia, IRCCS San Martino-IST, Genoa, Italy;

7. Hesperia Hospital, Modena, Italy;

8. AOU di Bologna, Policlinico S. Orsola-Malpighi, Bologna, Italy;

9. Ospedale Ferrarotto, Università di Catania, Catania, Italy;

10. AOU Integrata Verona, Verona, Italy;

11. AO Papa Giovanni XXIII, Bergamo, Italy;

12. IRCCS Policlinico S. Matteo, Pavia, Italy;

13. AO Brotzu, Cagliari, Italy;

14. AOU Policlinico Le Scotte, Siena, Italy;

15. AOUD Santa Maria della Misericordia, Udine, Italy;

16. AOU Careggi, Florence, Italy; 
17. Humanitas Research Hospital, Rozzano, Italy;

18. Ospedale Cattinara, Trieste, Italy;

19. Clinica S. Maria, Bari, Italy;

20. Ospedale Maggiore, Parma, Italy;

21. AO San Camillo Forlanini, Rome, Italy;

22. IRCCS Policlinico San Donato, Milan, Italy;

23. A.O. Cesare Biagio e Arrigo, Alessandria, Italy;

24. Istituto Clinico Sant'Ambrogio, Milan, Italy;

25. AOU Pisana, Pisa, Italy;

26. AOU Federico II, Naples, Italy;

27. Ospedale S. Chiara, Trento, Italy;

28. Clinica Mediterranea, Naples, Italy;

29. Città di Lecce Hospital, Lecce, Italy;

30. Policlinico Umberto I, Rome, Italy;

31. Ospedale Niguarda, Milan, Italy;

32. Università degli Studi di Tor Vergata, Rome, Italy 
Supplementary Table 1. Standardised difference for baseline features of patients according to antiplatelet regimen before and after propensity score with matching.

\begin{tabular}{|c|c|c|}
\hline & SD before propensity score & SD after propensity score \\
\hline Age (years) & 18 & 15 \\
\hline Body mass index $\left(\mathrm{kg} / \mathrm{m}^{2}\right)$ & 19 & 13 \\
\hline Female gender (\%) & 12 & 2 \\
\hline Diabetes mellitus (\%) & 0 & 1 \\
\hline Hypertension (\%) & 18 & 2 \\
\hline $\begin{array}{l}\text { Previous myocardial infarction (\%) } \\
<90 \text { days } \\
>90 \text { days }\end{array}$ & $\begin{array}{l}39 \\
13\end{array}$ & $\begin{array}{l}3 \\
2\end{array}$ \\
\hline Previous coronary artery disease (\%) & 20 & 2 \\
\hline Peripheral vascular disease (\%) & 8 & 1 \\
\hline $\begin{array}{l}\text { Chronic obstructive pulmonary disease* } \\
\text { (\%) }\end{array}$ & 2 & 0 \\
\hline Neurological dysfunction* (\%) & 10 & 5 \\
\hline $\begin{array}{l}\text { Ejection fraction: } \\
-\quad \% \\
\text { - } \quad \text { less than } 30 \%(\%)\end{array}$ & $\begin{array}{l}9 \\
10\end{array}$ & $\begin{array}{l}7 \\
9\end{array}$ \\
\hline $\begin{array}{l}\text { Renal function: } \\
\begin{array}{l}\text { - } \text { dialysis } \\
\text { - creatinine (mg/dl) } \\
\text { - clearance }\end{array}\end{array}$ & $\begin{array}{l}0 \\
13 \\
5\end{array}$ & $\begin{array}{l}2 \\
0 \\
2\end{array}$ \\
\hline Preoperative haemoglobin (g/dl) & 0 & 0 \\
\hline Atrial fibrillation before TAVI (\%) & 20 & 5 \\
\hline
\end{tabular}


Supplementary Table 2. Standardised difference for interventional features of patients according to antiplatelet regimen before and after propensity score with matching.

\begin{tabular}{|l|l|l|}
\hline & SD before propensity score & SD after propensity score \\
\hline Operative risk: & 0 & 0 \\
$-\quad$ STS & 15 & 13 \\
$-\quad$ EuroSCORE II & 22 & 15 \\
\hline Valvuloplasty as bridge to TAVI & 87 & 4 \\
\hline Access: & & 1 \\
$-\quad$ transfemoral & 23 & 2 \\
$-\quad$ transapical & 23 & 0 \\
\hline - transaortic & 3 & 0 \\
\hline Kind of device (\%): & 12 & 2 \\
\hline
\end{tabular}


Supplementary Table 3. Standardised difference (SD) for baseline features of patients according to antiplatelet/anticoagulation regimen before propensity score with matching.

\begin{tabular}{|c|c|c|}
\hline & SD before propensity score & SD after propensity score \\
\hline Age (years) & 18 & 16 \\
\hline Body mass index $\left(\mathrm{kg} / \mathrm{m}^{2}\right)$ & 25 & 21 \\
\hline Female gender (\%) & 20 & 0 \\
\hline Diabetes mellitus (\%) & 26 & 8 \\
\hline Hypertension (\%) & 10 & 9 \\
\hline $\begin{array}{l}\text { Previous myocardial infarction (\%) } \\
<90 \text { days } \\
>90 \text { days }\end{array}$ & $\begin{array}{l}6 \\
3\end{array}$ & \\
\hline Previous coronary artery disease (\%) & 30 & 5 \\
\hline Peripheral vascular disease (\%) & 12 & 6 \\
\hline $\begin{array}{l}\text { Chronic obstructive pulmonary disease* } \\
\text { (\%) }\end{array}$ & 2 & 6 \\
\hline Neurological dysfunction* (\%) & 0 & 0 \\
\hline $\begin{array}{l}\text { Ejection fraction: } \\
\begin{array}{l}-\quad \% \\
-\quad \text { less than } 30 \%(\%)\end{array}\end{array}$ & $\begin{array}{l}8 \\
0\end{array}$ & $\begin{array}{l}6 \\
4\end{array}$ \\
\hline $\begin{array}{l}\text { Renal function: } \\
\text { - dialysis } \\
\text { - creatinine (mg/dl) } \\
\text { - clearance }\end{array}$ & $\begin{array}{l}0 \\
13 \\
18\end{array}$ & $\begin{array}{l}0 \\
0 \\
5\end{array}$ \\
\hline Preoperative haemoglobin (g/dl) & 50 & 10 \\
\hline Atrial fibrillation before TAVI (\%) & 42 & 3 \\
\hline
\end{tabular}

*according to EUROSCORE definition 
Supplementary Table 4. Standardised difference (SD) for interventional features of patients according to antiplatelet/anticoagulation regimen before propensity score with matching.

\begin{tabular}{|c|c|c|}
\hline & $\begin{array}{l}\text { SD before propensity } \\
\text { score }\end{array}$ & SD after propensity score \\
\hline \multicolumn{3}{|l|}{ Operative risk: } \\
\hline - STS & 15 & 0 \\
\hline - $\quad$ EuroSCORE I & 22 & 8 \\
\hline - $\quad$ EuroSCORE II & 22 & 0 \\
\hline Valvuloplasty as bridge to TAVI & 24 & 12 \\
\hline \multicolumn{3}{|l|}{ Access: } \\
\hline - $\quad$ transfemoral & 48 & 2 \\
\hline - $\quad$ transapical & 48 & 2 \\
\hline - transaortic & 0 & 0 \\
\hline - trans-subclavian & 10 & - \\
\hline \multicolumn{3}{|l|}{ Kind of device (\%): } \\
\hline - SAPIEN & 43 & 2 \\
\hline - SAPIEN XT & 43 & 2 \\
\hline
\end{tabular}

